\title{
CUESTIONES BÁSICAS DE ÉTICA EMPRESARIAL
}

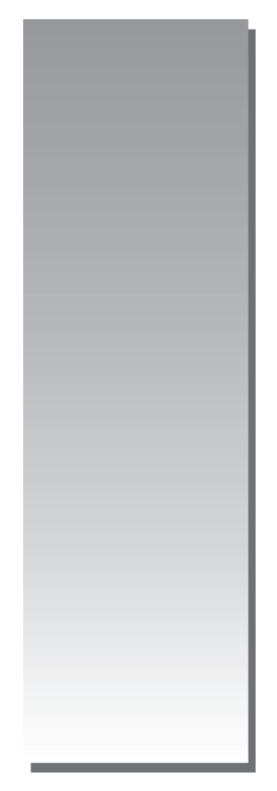

Miguel Ángel Polo Santillán (*)

E-mail:polotzu@yahoo.com

\section{RESUMEN}

El artículo analiza el sentido teleológico de la ética empresarial, vista como una institución cuyo sentido moral se encuentra en la relación con los stakeholders. Esta visión interrelacional permite entender el vínculo que existe entre la ética empresarial y la ética cívica, además de la importancia moral de la responsabilidad social empresarial, superando así la simple -aunque necesaria- visión deontológica de la ética empresarial.

Palabras clave: Ética, Ética Empresarial, Ética Cívica, Responsabilidad Social Empresarial.

\begin{abstract}
The article analyzes the teleological sense of the business ethics dress as an institution which moral sense meets in the relation the stakeholders. This interrelational vision allows to understand the relation that exists between the business ethics and the civic ethics, besides the moral importance of the corporate social responsibility, overcoming this way the simple one - though necessary deontological vision of the business ethics.
\end{abstract}

Key words: Ethics, Business Ethics, civic ethic, Commercial Social Responsibility.

(*) Profesor Principal de la Facultad de Letras y Ciencias Humanas UNMSM. Doctor en Filosofía. Magíster en Filosofía. Licenciado en Filosofía. 
La ética empresarial es una disciplina que empieza a tener un estatus propio desde la década de los 60 y 70 del siglo pasado, donde aparecen una serie de publicaciones y comienzan a dictarse cátedras de dicha materia. Podemos catalogarla como una ética aplicada cuya misión es pensar el sentido ético de la actividad empresarial. No obstante, desde su aparición, siempre han surgido dudas de parte de los escépticos. ¿No es una construcción ideológica o encubridora para justificar la actividad amoral (y hasta inmoral) de las empresas? ¿no es una cosmética o una instrumentalización de la ética más que una real ética? ¿por qué pensar que puede haber limitaciones éticas a una actividad que sólo se rige por las leyes del mercado? A veces, la realidad parece dar la razón a esas posturas (caso Enron, juguetes fabricados con sustancias tóxicas, explotación laboral, daño al medio ambiente, etc.), sin embargo también hay logros importantes (la efectiva puesta en práctica de la Responsabilidad Social Empresarial, la preocupación por el desarrollo humano de los trabajadores, la sensibilidad por el medio ambiente, etc.) que afirman la necesidad de seguir pensando y actuando en pro de empresas más éticas y humanas.

Además, las prácticas amorales o injustas de las empresas tradicionales requieren de muchos factores para ir mutando a nuevas formas más preocupadas por la moral y el bienestar personal y colectivo. En este artículo revisaremos algunos conceptos que se han estado usando en los trabajos de ética de empresa para ver nuevas aristas de su contenido así como sus implicancias. Nuestra perspectiva será ética antes que económica o administrativa.

\section{SENTIDO DE LA EMPRESA Y ÉTICA EMPRESA- RIAL}

La ética de la empresa ha venido a replantear el sentido mismo de la empresa, a develar su sentido metafísico y transformarla en un sentido más pragmático. La empresa, en sentido tradicional y metafísico, ha sido vista como una entidad única cuyo sentido se encuentra en su propia sobrevivencia, en persistir en su ser. En lenguaje empresarial, ha sido vista como una organización compues- ta por recursos humanos (obreros, empleados, funcionarios, supervisores), recursos materiales (maquinaria y equipo, edificios, materia prima y capital) y sostenido por un sistema administrativo. Es curioso es que esta organización económica que se sabe a sí misma como pragmática (es decir, no intelectual o teórica) se presenta como un ente metafísico. No hay nada más metafísico que esta visión de la realidad como ente único que se afirma a sí mismo (diferenciándose u oponiéndose, o "compitiendo" con los demás). Esta forma atomista de entender la empresa es la que está en cuestión en gran parte de los trabajos de ética empresarial.

La aparición de la teoría de los stakeholders ha venido a cuestionar y replantear la forma tradicional y metafísica de entender una empresa. Muchos autores solo la han entendido como grupos que pueden ser afectados por la actividad empresarial y ante los cuales la empresa debe responder; sin embargo, esta comprensión ética solo se sostiene si la empresa misma es entendida de manera diferente. Así, desde la teoría de los stakeholders, la empresa pierde su carácter de entidad cerrada y egocéntrica, visión atomista, para pasar a ser una realidad que debe su existencia a los stakeholders; es decir, una entidad que solo es posible por su interrelación con otras realidades, por lo que una empresa debe su ser y actividad a la relación que tiene con los trabajadores, los accionistas, los clientes, los proveedores, la sociedad, el Estado y el medio ambiente ${ }^{1}$. Si faltase uno de estos grupos, ¿podría sostenerse una empresa? No son solo grupos de interés sino grupos a los cuales debe su existencia, por lo que de ese reconocimiento surge el deber de cuidado y de dar respuestas por sus acciones. Sobre esta visión de interrelación puede tener sentido la ética empresarial y la responsabilidad social de las empresas. De lo contrario, seguirán siendo vistas como creencias y obligaciones que vienen de fuera y restringen la actividad económica de la empresa.

Desde esta perspectiva interrelacional, la empresa redefine sus finalidades. Hasta antes de los 70 era usual creer que la finalidad de la empresa -única o principal- era maximizar sus ganancias, obtener lucro ${ }^{2}$. Esa creencia ya no se sostiene tan

1 Para un tratamiento más amplio y sus consecuencias en la sociedad, ver: González, Elsa. (2007).

2 En 1970, Friedman escribía un artículo titulado "La responsabilidad social de los negocios es incrementar su beneficio" (ver Lozano. (1999). Págs. 86-93; Paladino y Milberg. (2007). Pág. 41), mientras que en la década de los 90 el economista Sen sostenía que el bienestar económico depende de las capacidades humanas y de condiciones como libertad e igualdad social. Con esto se replantea el rol de los derechos humanos en el mundo empresarial. 
fácilmente en nuestro tiempo. El mantra maximini (maximizar ganancias, minimizar pérdidas) ya no pude justificar la existencia social de las empresas.

Jesús Conill redefine esas finalidades correctamente para estos nuevos tiempos:

“1) producir bienes y/o servicios, 2) aumentar el valor económico añadido (lograr beneficios), a fin de: a) atender las rentas de trabajo y de capital y b) poder invertir para garantizar la viabilidad de la empresa; pero también tiene como objetivos: 3) promover el desarrollo humano y 4) garantizar la continuidad de la empresa"3.

Esta forma de entender las finalidades de la empresa ya expresa un sentido ético de la misma porque, por ejemplo, la finalidad de producir bienes y/o servicios implica el compromiso de satisfacer alguna necesidad o deseo de la sociedad; su satisfacción es un elemento indispensable para justificar la existencia de una empresa. La forma de entender esta finalidad de la empresa, pensada por Cortina, añade un elemento importante:

"El fin de las empresas, aquello que ninguna otra actividad puede hacer por ellas, consiste en satisfacer necesidades humanas con calidad, creando riqueza. Y tienen que hacerlo, a fines del siglo $X X$, percatándose que cuantos participan en ellas (empleados, accionistas, consumidores, proveedores, competidores, entorno social) son interlocutores válidos, que han de tenerse en cuenta a la hora de tomar decisiones que les afectan. Las relaciones de corresponsabilidad, comunicación y transparencia son las adecuadas a este nivel de exigencia, el contrato estable y la formación continua"4.

Así, en la medida que la empresa reconozca sus lazos vitales con los stakeholders, los asumirá como interlocutores válidos, cuya voz deberá ser tomada en cuenta.
Por ello surge la responsabilidad ante los clientes o usurarios por la calidad del bien o servicio dado. Los clientes y usuarios no pueden ser asumidos como objetos o partes del proceso productivo y económico. Ese paulatino reconocimiento de la dignidad de los consumidores o clientes es impulsado por el reconocimiento que los propios consumidores tienen de su dignidad, lo que les lleva a defender y luchar por sus derechos y crear organizaciones que los defiendan ante las arbitrariedades e injusticias del poder empresarial. Así, la lucha por el reconocimiento de los derechos de los usuarios ha permitido crear mayor conciencia en las empresas, por lo que ahora deben cuidar de la calidad de los bienes y servicios que ofrecen. Una vez más, quizá con esas luchas por el reconocimiento - como lo ha sostenido Axel Honneth-, las empresas vayan transformando su naturaleza moral.

Asimismo, la ética de la empresa no tiende a eliminar la preocupación empresarial por la "rentabilidad", por maximizar los beneficios económicos, por la ganancia. Después de todo, la historia de las organizaciones lucrativas ha enseñado que sin rentabilidad no hay viabilidad para una empresa. Sin embargo, la ética de la empresa pone este ideal o interés económico en el contexto de encuentro con otros ideales e intereses sociales legítimos como pueden ser la dignidad, el respeto, la justicia, los derechos humanos y, claro está, también los derechos medioambientales. La apología de la rentabilidad que a veces se justifica por el bienestar social, se convierte en encubridora de una realidad injusta cuando este valor no se encuentra ligado a otros considerados fundamentales en la vida contemporánea ${ }^{5}$, por lo que la condición de la ética empresarial no es que sea una ética desinteresada o, dicho de otro modo, la incorporación de criterios éticos en la empresa no tiene que suprimir sus intereses económicos sino integrarse a ellos. Como sostiene Lipovetsky:

“...resulta manifiesto el carácter instrumental de la ética de los negocios impulsada por el

3 Conill, Jesús (1996). Pág.70.

4 Cortina. (1998). Pág. 145.

5 Gordon Gekko, uno de los personajes centrales de la película Wall Street, nos trae un texto que probablemente resume muy bien el espíritu de los negocios sin consideraciones morales: "El caso es, damas y caballeros, que la codicia, por falta de una palabra mejor, es buena. La codicia es apropiada. La codicia funciona. La codicia clarifica, penetra y captura la esencia del espíritu evolutivo. La codicia, en todas sus formas, la codicia por la vida, por el dinero, por el amor, por el conocimiento, ha marcado un impulso hacia arriba para la humanidad. Y la codicia, recuerden mis palabras, no solo salvará a Papel Telder, sino también a esta corporación con tantas fallas, Ilamada Estados Unidos." Ideas ya presentes en La fábula de las abejas de Mandeville (s. XVIII). 
interés vital de las empresas. La moral se ha transformado en medio económico, en herramienta de gestión, en técnica de gestión de empresas"6.

En la misma dirección de Sen, Conill coloca como finalidad de la empresa "promover el desarrollo humano”. En la antiguiedad, Aristóteles separaba los fines de la vida, ética y los fines de los negocios, sobrevalorando los primeros y menospreciando los segundos. Y es que solo la finalidad ética abarcaba lo que llamamos hoy desarrollo humano. Pero nuestro tiempo, luego de tantos encuentros y desencuentros, se replantea esta visión y busca esos puentes necesarios entre ambas actividades. Los negocios también pueden tener un sentido ético, lo cual involucra pensar en el desarrollo humano de las personas que componen la empresa así como pensar en los proyectos personales de los consumidores y miembros de la sociedad (ya que las acciones de las empresas afectan los proyectos de realización personal). Extendiendo un poco más la reflexión, diríamos con Kliksberg que el desarrollo económico ya no puede considerarse como primero para dejar para después el desarrollo de los valores y la cultura. Una nueva visión nos lleva a integrar ambas formas de desarrollo para que pueda denominarse desarrollo humano ${ }^{7}$.

Finalmente, podemos encontrar ese sentido ético de las empresas si las redefinimos como organizaciones que sostienen una actividad humana. Y, como afirma Cortina:

“... la actividad empresarial es actividad humana $y$, por tanto, puede ser moral o inmoralmente llevada a cabo; que la empresa, como institución, tiene repercusiones sociales $y$, por ello, es la sociedad quien tiene que darla por buena; $y$, por último, que la empresa, como organización, es un conjunto de personas, cuyas relaciones pueden ser humanizadoras o deshumanizadoras"8.

Esto último es posible porque las organizaciones se orientan y funcionan con valores cuya realización afecta a las personas que la integran así como a la sociedad ${ }^{9}$

Así, el sentido ético de la empresa está en función de los fines que debe realizar, y dichos fines son replanteados y ampliados desde hace unas décadas por la sociedad, el mundo académico, la propia actividad empresarial y las nuevas exigencias del mercado.

\section{¿PARA QUÉ SIRVE LA ÉTICA EMPRESARIAL?}

Si la ética aparece cuando se hace presente el otro, entonces surgen una serie de cuestiones típicas de la reflexión ética: ¿puedo utilizar al otro como quiero? ¿se justifica subyugar al otro? ¿qué normas se hacen indispensables en mi relación con el otro? ipuedo prepararme de un modo específico para tener una relación ética con el otro o estoy determinado por la naturaleza o la sociedad? ¿es la violencia una salida cuando el otro se siente oprimido? ipodemos instaurar condiciones sociales para una convivencia social decente y humana? isoy responsable del destino del otro? Todas estas cuestiones han sido inspiradoras de teorías éticas a lo largo de la historia. Estas mismas preguntas pueden ser planteadas en relación con la empresa. En ese marco, ¿para qué nos puede servir la ética en la empresa? Como disciplina aplicada, podemos señalar por lo menos tres grandes respuestas:

6 Lipovetsky. (2003). Pág. 73. Más adelante señala que es preferible la instrumentalización de la ética a la falta de ella en la empresa: "Creo que debemos animar esta instrumentalización de la ética, en especial en lo que concierne a las políticas de solidaridad, y ello porque refuerzan y difunden la legitimidad social de la idea misma de solidaridad. A fin de cuentas, siempre será mejor que la ideología del egoísmo seguro de sí mismo y de la indiferencia moral". Op. cit. (2003). Pág. 84.

7 El texto de Kliksberg es el siguiente: "Los modelos de desarrollo convencionales postulaban que primero viene el desarrollo económico, que después éste se 'derramaría' y habría desarrollo social, y dejaban para el final el desarrollo de la cultura y los valores. Hoy en día, los fracasos enseñan que la vía es diferente. El desarrollo económico y el social deben darse conjuntamente para que haya real desarrollo... Ahora se sabe también que cultura y valores no son una tercera etapa: tienen que formar una parte integrada del desarrollo. Sin una población bien preparada y saludable, y cultura, confianza mutua y valores éticos, los aparentes logros económicos pueden ser efímeros". Kliksberg. (2002). Págs. 146-147. Esto es relevante, especialmente en nuestro país, porque esa perspectiva hace ver que para los políticos primero es el crecimiento económico, sin invertir significativa y paralelamente en las áreas de educación y salud, y parece que la cultura está al final, como lo muestra la escasa o nula preocupación por la calidad e inversión en las universidades públicas.

8 Cortina. (1998). Pág.141.

9 Recordemos que a nivel de ética de las organizaciones, hoy se viene trabajando términos como "organizaciones enfermas", "organizaciones sanas" y "organizaciones excelentes", todo lo cual ya supone considerar a las organizaciones como sujetos éticos a quienes se les puede atribuir responsabilidades. Para una presentación del debate ver Lozano. (1999). 
1. Fundamentación. Nuestras acciones se sostienen en ciertas ideas que tienen que ser asumidas lo más claramente posible. Se trata de dar buenas razones para justificar nuestra praxis personal, social e institucional. Por ejemplo, tenemos que dar razones al por qué es necesaria la reflexión ética en el campo de los negocios. Las diferentes teorías éticas nos ayudan a dar esa respuesta, aunque ninguna de ellas puede darnos una visión completa ni reemplazar nuestras decisiones personales. $Y$ nuestras buenas razones solo pueden ser tales después de ser puestas en el espacio público, ámbito de discusión con otros que tienen sus propias razones.

2. Crítica. Frente a los escépticos que miran a la ética empresarial como cosmética, es necesario resaltar su función crítica; es decir, desenmascaradora de los factores que crean relaciones y estructuras de dominio e injusticia de un grupo sobre otro. El sentido excesivamente optimista o pragmático de un discurso ético en los negocios puede ser encubridor de realidades injustas, así es necesaria una buena dosis de perspectiva crítica y autocrítica para ver las incoherencias de las prácticas humanas y analizar los presupuestos que éstas esconden. Por eso, no se pueden desechar las críticas que se hacen a la ética empresarial por verla más como cosmética que como auténtica ética. Por ejemplo, la Responsabilidad Social Empresarial (como inversión en educación o deportes) puede encubrir prácticas injustas al interior de la empresa con respecto a salarios, seguridad, derechos de sindicalización, etc. Como en cualquier actividad humana, la actividad de los negocios está llena de mitos, prejuicios y leyendas que las propias organizaciones mantienen pero que deben ser evaluados y quizá reinventados para integrarlos a las exigencias éticas de nuestro tiempo.

3. Toma de decisiones. Por esta razón, la ética empresarial debe ser capaz de ofrecer criterios, procedimientos y marcos teóricos que nos permitan tomar las mejores decisiones, éticamente hablando. No cabe duda que la perspectiva norteamericana de la ética empresarial o ética de los negocios ha estado guiada principalmente por esta tendencia, y es que en la experiencia diaria se presentan casos o situa- ciones problemáticas, por lo que las personas e instituciones requieren procedimientos para manejarse en esas situaciones.

4. Cultura empresarial. Es la parte constructiva de la ética empresarial. La afirmación de la ética de la empresa va creando una cultura que integra el bienestar económico con el desarrollo humano, donde los sujetos sienten que van realizando su vida personal en el proceso de crear riqueza social; una cultura que apueste por los valores humanos mejor logrados socialmente y que asuma que

“...la confianza vende, la credibilidad vende, la calidad es la mejor propaganda; $y$ que, por el contrario, la chapuza disuade, el engaño enseña al cliente que 'una y no más', la falta de calidad hunde a la empresa"10.

Esto lleva a organizar la empresa y gerenciarla en función de esos valores que fomentan el desarrollo humano en sus distintos aspectos.

No cabe duda que dos claves éticas irrenunciables de esta cultura empresarial deben ser el respeto y la justicia: el saber que como humanos no debemos hacer del otro lo que queramos porque hay mínimas normas de convivencia que tenemos que respetar si queremos vivir humanamente. Nuestros intereses de realización personal o institucional no pueden faltar a lo conquistado socialmente: los derechos humanos; de lo contrario, siempre crearemos condiciones para la protesta y la violencia, puertas siempre abiertas cuando las sociedades e instituciones carecen de un sentido de justicia.

\section{EL BUCLE ÉTICA EMPRESARIAL - ÉTICA CÍVICA}

Una de las claves interpretativas de la ética de empresa nos la ha dado la filósofa Adela Cortina ${ }^{11}$ cuando hace una doble afirmación: "No es posible una ética empresarial sin una ética cívica" y "No es posible una ética cívica sin una ética empresarial". Nosotros queremos entenderla de la siguiente manera.

\section{1. "No es posible una ética empresarial sin una ética cívica".}

La cultura empresarial se encuentra en un contexto social determinado, el cual orienta el carácter moral de la organización empresarial.

10 Cortina. (1998). Págs. 137-138.

11 Cortina. (1996). Págs. 42-44. 
Queremos entender por ética cívica a aquella cultura que los ciudadanos van constituyendo para hacerse responsables de sus propias vidas en el contexto de convivencia social, así van creando un mundo social de respeto por las normas y valores mínimos de convivencia con la finalidad de posibilitar la realización de vidas personales plenas y felices.

Parafraseando a Cortina, los ciudadanos asumen mínimos de justicia para crear máximos de felicidad. Esos mínimos de convivencia incluyen los derechos humanos en torno a los cuales se organizan las sociedades democráticas actuales. Son esos valores, ideales y principios ganados por la experiencia humana los que a su vez se constituyen en marcos para la formación sensata de las empresas que atienden no solo a las exigencias de ganancias, sino también a las necesidades y al bienestar humano. Por eso, solo pensando la ética empresarial en el marco de la ética cívica, es que la primera puede adquirir sentido.

La simple exigencia de ganancia hoy no puede justificar la existencia de las empresas, porque esa exigencia por sí sola también es compartida por las organizaciones delictivas. Las empresas sólo pueden marcar sus diferencias a través de la asunción de valores socialmente compartidos como el respeto, la honestidad, la solidaridad, el bien común, la justicia, etc. La visión de las empresas como grandes corporaciones impersonales que se autojustifican solo por el deseo de lucro debe ceder a la visión de las empresas que se entienden como partes sustantivas de un todo social y humano que les da sentido, que buscan la sostenibilidad económica en el tiempo y que son el sustento para el bienestar de las personas y las colectividades.

\section{2. "No es posible una ética cívica sin una ética empresarial".}

Hoy las empresas tienen un rol social fundamental, no solo en la economía sino también en la formación social y cultural. Son las organizaciones las que generan riqueza y bienestar a la sociedad; con ello van generando formas de relaciones sociales, afirmando valores y mentalidades que afectan a la sociedad. Así, también se podría afirmar que la calidad moral de una sociedad se debe a la calidad moral de sus organizaciones.

No sólo la sociedad y el Estado pueden generar y alimentar moral o inmoralmente a las organi- zaciones sino también las organizaciones, sobre todo las que tienen más relevancia social como las empresas, pueden influir positiva o negativamente en la sociedad y el Estado. Las empresas, pues, pueden constituirse en elementos que afirmen los valores socialmente logrados, contribuir al bienestar social tanto material como moral y espiritual, y no sólo porque el bienestar material sea sustento de los posteriores logros culturales, sino porque sus creencias, normas y valores se trasmiten socialmente.

Dicho en breve: las empresas pueden reproducir las virtudes y vicios de la sociedad así como también pueden generar virtudes y vicios en la sociedad. Y si los empresarios tienen una visión de sociedad más amplia que la de simplemente "competir y ganar", podrán apostar a ser agentes de transformación moral en la sociedad, lo cual no es moralismo porque estamos entendiendo la moral como ese conjunto de valores que nos hace constituirnos como seres humanos, personal y colectivamente.

\section{La ética cívica.}

En una de mis clases de ética preguntaba a los alumnos: ¿qué diferencia hay entre los negocios realizados por las empresas legalmente constituidas con los negocios realizados por las empresas del padrino Vito Corleone? ¿es sólo el estar al margen de la ley? ¿es por guiarse por los criterios de rentabilidad sin consideración de ningún otro valor? ¿es por medir a las personas según su utilidad para los negocios o su peligro para los mismos? ¿es porque logra formar lazos que comprometen a las personas a riesgo de sus vidas? ¿será porque no eran negocios morales?

Recordemos que los negocios del Padrino eran exitosos, es decir, rentables, criterio tan anhelado por el mundo de los negocios. Pero aún así podemos preguntar: ¿rentables económicamente para quién? ¿y a costa de qué? No cabe duda que la película El Padrino puede ser un buen comienzo para todo curso sobre ética empresarial o ética de los negocios, porque genera un conjunto de cuestiones que siguen gravitando en los negocios hasta nuestros días.

Las reflexiones que siguen las haremos desde lo que consideramos una "ética cívica". La comparación que haré no será entre los negocios ilícitos del Padrino y los negocios legales contemporáneos, sino entre los negocios inmoralmente 
constituidos y los moralmente constituidos, ya que el estar dentro de un marco legal no los hace ipso facto morales.

Una de las diferencias más importantes entre los negocios del Padrino con respecto a los negocios constituidos moralmente es que los primeros no respetan ningún mínimo logrado socialmente. Así, la dignidad de los seres humanos es constantemente pisoteada como en cualquier organización criminal; las personas son medidas según su utilidad presente o futura para la empresa y, como en todo grupo de delincuentes, también ellos trazan los límites de su propia moral.

Algo especialmente significativo de la película es el rechazo del Padrino a entrar en los negocios de la droga, él quiere quedarse con sus negocios habituales. ¿Lo hace por reconocer la dignidad humana? No. Lo hace porque ese negocio tiende a destruir a los sujetos que lo hacen poderoso y rico. Es en función a la rentabilidad futura de sus negocios que se niega a participar. Aunque también puede ser leído su rechazo por su modo tradicional de ser italiano, que valora la familia y los lazos comunitarios, mientras la droga tiende a separar a las familias y romper esos lazos, lo cual quiere decir que aún los delincuentes no borran del todo el hábito formado socialmente. O como dice la leyenda, el narcotraficante Pablo Escobar ayudaba económicamente al pueblo donde se crió. Sin embargo, no han incorporado en ese hábito el respeto a los seres humanos ni valoran la dignidad o valor que poseemos.

La falta de consideración por los derechos humanos básicos también es un asunto de poder. Vito Corleone era un "empresario" que tenía poder, no sólo económico (porque controlaba la mayoría de negocios de los italianos) sino también político (porque contaba con el apoyo de políticos, jueces y policías). Por eso, terminar con su vida se convirtió en un imperativo para los que querían apostar por nuevos negocios ${ }^{12}$. Una vez más, la ética de la empresa no debiera dejar de pensar en el tema del poder económico y político porque la forma como consideremos su relación afectará a los negocios y a la sociedad. Esto nos lleva a la siguiente pregunta: ¿qué tipo de sociedad y Estado requerimos para posibilitar que las empresas realicen sus funciones y tengan sentido moral? Porque dejarlas a su albedrío no garantiza su transformación. Este es un tema tanto de la ética como de la filosofía política que solo podemos dejar planteado.

Así pues, son los derechos humanos aquellas expresiones de nuestra autovaloración, de cómo vamos pensándonos como seres humanos para convivir y autorrealizarnos. Y las organizaciones al estilo del Padrino, que justamente desconocen esos derechos o en todo caso solo pretenden reconocérselos para ellos y sus allegados, impiden tal convivencia y autorrealización. Queda claro, pues, el tipo de sociedad que podría generarse si las empresas se constituyen como fines en sí mismas, sin atender a los valores mínimos que requiere una sociedad moralmente sostenible.

\section{RESPONSABILIDAD SOCIAL EMPRESARIAL: DEFINICIÓN E IMPLICANCIAS}

Si la empresa reconoce su existencia a partir de una red de relaciones, de esa conciencia surge la preocupación por dar respuesta a ese entorno en el que se desenvuelve. No basta el buen servicio o buen clima laboral, sino que se requiere del reconocimiento de los lazos sustantivos que tiene con el entorno. Sobre ese supuesto ético puede organizarse, en función de dar razones de sus acciones y contrarrestar los impactos de sus actividades negativas. Por eso, tampoco es un acto de filantropía sino una expresión de la toma de conciencia de su lugar en el mundo y en la sociedad.

Como toda responsabilidad, la RSE es una respuesta. La persona y la empresa responsables dan respuesta por sus decisiones, acciones y consecuencias. Y como lo ha señalado Vallaeys, la respuesta tiene dos componentes: dar respuesta por las pretensiones e impactos (responder por) y dar respuesta a las partes interesadas y afectados (responder a $)^{13}$. Y volvemos a señalar: alguien res-

12 Los defensores de la economía moderna podrán sostener que la diferencia básica es que en la película no se trabaja bajo el trasfondo del libre mercado, porque eso es justamente lo que no existe. El libre mercado no solo incluye la participación libre de vendedores y compradores sino también la libre competencia, que no es el caso en la película. Sin embargo, esto es trasladar el problema, no solucionarlo, porque todavía podemos preguntarnos: ¿tiene sentido moral el libre mercado? ¿y el libre mercado es el único criterio absoluto que debe regir las relaciones económicas? ¿no está el libre mercado también envuelto en creencias y valores de los agentes que participan en él? Cuestiones importantes que exceden a nuestras pretensiones en este artículo.

13 Vallaeys. (2006). 
ponde porque se siente comprometido a hacerlo y, a su vez, el compromiso requiere comprensión o conciencia de los nexos vitales con los stakeholders. Pero esa conciencia no surge espontáneamente sino que es expresión de la presencia del otro que exige, reclama, lucha, defiende su dignidad y sus derechos ${ }^{14}$.

Con este antecedente podemos preguntarnos: ¿qué es entonces la RSE? Una definición que integra diversos elementos (gerencia, investigación, calidad, ética y democracia participativa) es ofrecida por Vallaeys:

"Precisando esta definición podemos mencionar que la responsabilidad social es: (1) Una política de gestión de impactos (es gerencia, no mera iniciativa aislada),

(2) basada en la medición y el diagnóstico permanente de todos los procesos de la organización (es investigación diagnóstica, no simple declaración de principios sin objetividad ni autoexamen),

(3) que busca la mejora continua de todos los productos e impactos de la organización (es proceso de calidad, corrección continua de errores, no es hacer la revolución y cambiarlo todo de una vez),

(4) para la mayor satisfacción posible de todas las partes interesadas y afectadas por la existencia de la organización (es ética, relación gana-gana con las partes implicadas, acatamiento de normas universales, no defensa de los intereses de algunos contra otros),

(5) asociándose, dialogando y creando sinergia entre todos los actores necesarios para lograr el mayor impacto social posible (es democracia participativa, creación de capital social $y$ redes de desarrollo, no es imaginarse uno mismo como dueño exclusivo de la solución a todos los problemas sociales, o contentarse con acciones aisladas de poco alcance)"15.

La RSE es un concepto que abarca la obligación moral que tiene la empresa con respecto a terceros (sociedad, sectores menos favorecidos, etc.). Es un deber imperfecto pues surge cuando la empresa es consciente de su lugar y compromiso con la sociedad donde realiza sus actividades, por lo que el Estado no puede obligar a las empresas a realizar proyectos sociales aunque sí puede crear condiciones para que los realicen, como reducción de impuestos. Claro está que la RSE no pretende suplantar el trabajo del Estado, sino reconocer que el bien común, en las condiciones sociales y económicas actuales, no es tarea solo del Estado.

Por eso se puede sostener que la RSE es una nueva forma de pensar en el bien común, en la medida que colabora con el desarrollo social, económico y cultural de la sociedad. Una parte de la sociedad civil, en este caso organizada en una empresa, asume el compromiso del desarrollo de la propia sociedad.

¿Qué asuntos o temas abarca la RSE? El Grupo de Trabajo de la ISO sobre Responsabilidad Social ha señalado los siguientes temas que involucra la $\operatorname{RSE}^{16}$ :

- Respeto por los instrumentos internacionalmente reconocidos.

- Cumplimiento de las leyes.

- Reconocimiento de los derechos de los stakeholders.

- Rendición de cuentas.

- Transparencia.

- Desarrollo sostenible.

- Conducta / comportamiento ético.

- Criterio de precaución.

- Primacía del respeto por los derechos humanos fundamentales.

- Respeto por la diversidad.

Estos temas a veces son agrupados en asuntos sociales, ecológicos y económicos. Esta lista es importante justamente para que no quede en

14 Como triste ejemplo podemos señalar el derrame de mercurio de la minera Yanacocha producido en el 2000 y que, hasta la fecha, dicha minera no ha cumplido con la reparación satisfactoria exigida por la Municipalidad Provincial de Cajamarca, que entabló una demanda contra ella por US\$ 20 millones. Para mayor información, ver: http://ecoportal.net/ ¿Qué hace que una trasnacional, sabiendo del impacto social y ecológico de ese desastre, no pueda reconocer sus faltas ante una corte y aceptar las penas que corresponden por los daños ocasionados? ¿Será la soberbia del poder? ¿Será la justicia de su inocencia?

15 Vallaeys, François. (2008). Pág. 28. En la misma obra ver: "Evolución del concepto de responsabilidad social empresarial", de Fernando D’Alessio y Percy Marquina.

16 Informe del Grupo de Trabajo de ISO sobre Responsabilidad Social: El desarrollo del futuro estándar ISO SR 26000. Slob, Bart y Oonk, Gerard. (2007). 
declaraciones moralistas, pero además requiere de un sustento en la organización, es decir, se requiere gerenciar estos aspectos para que puedan ser evaluados posteriormente. Así, aparecen dos elementos adicionales en la constitución de la RSE: no basta la conciencia y el compromiso de responder, se requiere además que la empresa se organice en función de esa tarea y que esté dispuesta a ser evaluada por entidades competentes con criterios imparciales ${ }^{17}$.

Sin la RSE, la empresa corre el riesgo de identificarse con las organizaciones delincuenciales. Éstas últimas viven para sí mismas aunque se caiga el mundo, como es el caso de las organizaciones de narcotraficantes. Por eso, si algo diferencia a las organizaciones empresariales de las delincuenciales es la RSE, es decir, su compromiso con el entorno que les permite su actividad. Consecuentemente, las empresas que talan ilegalmente en la Amazonía pueden ser consideradas delincuenciales en tanto combinan en sus acciones ilegalidad, corrupción e inmoralidad, sin mayor consideración por las razones ecológicas actuales.

\section{DERECHO Y ÉTICA}

Aunque existe una estrecha relación entre la dimensión jurídica y la moral, no se puede reducir una a la otra. Las exigencias morales, mediadas por procesos históricos, han resultado en declaraciones y normatividades jurídicas que los Estados están obligados a cumplir. Así lo podemos ver con los derechos humanos, cuyas exigencias teóricas y sociales se han plasmado en el derecho contemporáneo. Es la dimensión moral una de las fuentes de las que se nutre el derecho, y cosa semejante puede ocurrir con las reflexiones éticas y las exigencias sociales, económicas y medioambientales, de mayor exigencia en los negocios y en el mundo de la economía.
Dicho esto podemos apreciar que el mundo normativo, tanto moral como jurídico, ya está rigiendo las actividades de las empresas. Existen códigos y declaraciones internacionales que las empresas no pueden desconocer, como la Declaración de la Organización Internacional del Trabajo (OIT) relativa a los principios y derechos fundamentales en el trabajo ${ }^{18}$. Los Estados deben tener en cuenta esos documentos internacionales en el momento de legislar sobre políticas laborales y económicas.

Desde el nivel deontológico se puede afirmar que las empresas están obligadas frente a ese marco jurídico nacional e internacional. Sin embargo, lo jurídico no abarca todo lo moral, por lo que existe todavía mucho espacio para la creatividad moral en las empresas. Así, buena parte de las empresas establecen sus propios códigos de ética ${ }^{19}$ y desean ser evaluadas por estándares internacionales de calidad que permitan organizar, gerenciar y medir sus impactos en distintos rubros como el medio ambiente, lo cual quiere decir que el futuro ético de las empresas todavía tiene mucho margen de acción para superar así la denominación de organizaciones psicópatas $^{20}$.

\section{BIBLIOGRAFÍA}

Conill, Jesús. (1996). "Marco ético-económico de la empresa moderna", en Cortina, Adela. (año). Ética de la empresa. Claves para una nueva cultura empresarial. Madrid, Ed. Trotta.

Cortina, Adela. (1996). "La ética empresarial en el contexto de una ética cívica”, en Cortina, Adela. (año). Ética de la empresa. Claves para una nueva cultura empresarial. Madrid, Ed. Trotta.

17 Eso hace que sean necesarios los estándares de Responsabilidad Social como el Estándar de Aseguramiento AA1000 preocupado por el desarrollo sostenible, el ISO 14000 o ISO Verde, la Responsabilidad Social 8000 o Norma SA 8000, entre otros. Todos estos reconocen su carácter perfectible, por lo tanto sujetos a cambios según las exigencias de los tiempos.

18 Recordemos los convenios fundamentales logrados por la OIT: la eliminación del trabajo forzoso, la libertad sindical y protección del derecho de sindicación, igualdad de remuneración entre hombres y mujeres, discriminación laboral, prohibición y eliminación del trabajo infantil, entre otros.

19 Podemos poner como ejemplo el Código de Ética de Ericsson http://www.ericsson.com/es/ericsson/documentos/codigo_etica_ conducta.pdf, asimismo el Código de Conducta del Citibank: http://www.citigroup.com/citi/corporategovernance/data/codeconduct_ es.pdf

20 El documental titulado "La Corporación” presenta a las grandes empresas como psicópatas, lo cual no es una exageración luego de mostrar muchos casos donde las empresas han ido contra los consumidores, la sociedad y el medio ambiente. Sin embargo, depende de las mismas empresas que construyan una organización ética que sea espacio para el desarrollo humano, tanto interno como externo. Lo que sea la empresa depende de todos los que están involucrados en torno a ella. 
Cortina, Adela. (1998). Hasta un pueblo de demonios. Ética pública y sociedad. Madrid, Ed. Taurus.

González, Elsa. (2007). La teoría de los stakeholders. Un puente para el desarrollo práctico de la ética empresarial y de la responsabilidad social corporativa. Valencia, Fundación ÉTNOR.

Kliksberg, Bernardo. (2002). Hacia una economía con rostro humano. Maracaibo, Universidad de Zulia.

Lipovetsky, Gilles. (2003). Metamorfosis de la cultura liberal. Ética, medios de comunicación, empresa. Barcelona, Ed. Anagrama.

Lozano, Josep M. (1999). Ética y empresa. Madrid, Ed. Trotta.
Palatino, Marcelo (editor). (2007). La responsabilidad de la empresa en la sociedad. Buenos Aires, Emecé Editores.

Vallaeys, François. (2008). "La responsabilidad social universitaria”. En: Revista Brújula. Año 9, № 16, abril-julio 2008.

\section{INTERNET}

Organización Internacional del Trabajo. La OIT: Qué es, Qué hace. En: www.ilo.org/communication

Slob, Bart y Donk, Gerard. (2007). El desarrollo del futuro estándar ISO SR 26000. Informe del grupo de trabajo ISO sobre Responsabilidad Social. Revisado el 21 de marzo de 2007. Ver: http://www.choike.org/documentos/ ISO_SR_26000_esp.pdf 